\title{
TEORIA E METODOLOGIA DE REDES SOCIAIS NOS ESTUDOS DA INFORMAÇÃO: CRUZAMENTOS INTERDISCIPLINARES
}

O número pretende, além de apresentar um panorama do emprego teórico e metodológico dos conceitos de rede e redes sociais no campo de estudos da informação, situar seus fundamentos críticos nas ciências sociais e as oportunidades do seu uso para organizar ações coletivas nos tempos atuais do mundo globalizado, onde as questões da informação, do conhecimento e da comunicação marcam presença de forma especial. Por isso mesmo, o intento das organizadoras do número temático é de reunir trabalhos que permitam vislumbrar tanto a diversidade disciplinar, quanto as confluências interdisciplinares dos estudos sobre redes e redes sociais.

Dentre uma grande produção de obras que se dedicam desde os últimos anos ao estudo do conceito de rede, Parrochia o descreve como "um conjunto de objetos interconectados e reunidos por suas trocas de matéria ou de informação", num percurso que passa pela matéria mais repetitiva ao pensamento mais diferenciado, atravessando o domínio da reticularidade objetiva dos espaços con- cretos geográficos ou edificados, as redes de telecomunicações e de satélites. É preciso ainda estudar a maneira como essas redes materiais e concretas se refletem no imaginário social e registram essas circulações e configurações de redes precedentes: redes bancárias ou econômicas, de relações internacionais, redes de resistências ou de influências, sistemas de difusão de saberes e de técnicas.

A noção de redes sociais, por outro lado, designa geralmente conjuntos de relações entre pessoas ou grupos sociais, e vem se expandindo progressivamente, tanto no interior quanto nas fronteiras das ciências sociais.

Boltanski e Chiapello observam que o número de ocorrências da palavra "rede" na literatura de gestão, por exemplo, multiplicou-se por mais de 20 entre os anos de 1960 e 1990.

Nesse fascículo especial da revista Informação \& Informação dedicado ao tema das redes, redes sociais e informação, nossa proposta não é a de chamar a atenção para a novidade desses concei- 
tos no estudo de sociedades ou organizações, que hoje funcionaram em forma reticular. O intento é de reunir reflexões e práticas de pesquisa para configurar um conjunto de métodos, conceitos e teorias capazes de jogar luz sobre as questões mais fundamentais do campo de estudos da informação, que dizem respeito aos processos de produção e organização da informação e suas mediações para alcançar a apropriação e o uso efetivo dos conhecimentos produzidos socialmente.

Trata-se, portanto, de um recorte temporal num campo de pesquisa que cada vez mais desperta o interesse dos estudiosos da informação e de temas ou fenômenos afins.

O fascículo está composto de quatro seções. Os autores que assinam o conjunto de artigos da primeira seção são pesquisadores que atuam nas áreas de ciência da informação, ciências sociais, saúde e comunicação.

No primeiro artigo dessa primeira seção, "Redes sociais e teoria social revendo os fundamentos do conceito", Sonia Acioli discute usos e abordagens empregados para estudar as redes sociais, ressaltando que ultimamente a noção tem sido naturalizada e associada preferencialmente às tecnologias da informação. Para cumprir seu propósito, realiza uma incursão nos campos da sociologia, antropologia, informação e comunicação.
Em seguida, para refletir sobre as possibilidades de análises utilizando a noção de redes sociais, apresenta três abordagens - metafórica, analítica e tecnológica - inspiradas na leitura de dois clássicos dessa temática, que são os antropólogos John A. Barnes, que foi quem primeiro introduziu a noção de "redes sociais" na ciência social, e J. Clyde Mitchell. Nas três abordagens a autora percebe uma relação complementar entre os conceitos de redes sociais e informação, entendendo esta última como processo de troca permanente.

No segundo artigo da primeira seção, "Formas de organização e enredamento para ações sociopolíticas", Sonia Aguiar ressalta que as diversas formas organizativas baseadas em dinâmicas de enredamento entre organizações nãogovernamentais (ONGs) e movimentos sociais se diferenciam das redes sociais de indivíduos, porque seus nós representam interesses, necessidades e identidades coletivas de grupos, comunidades e populações. Suas ações são portanto coletivas e envolvem processos participativos e colaborativos fortemente apoiados em produção, apropriação e compartiIhamento de conhecimento e saberes especializados, que orientam escolhas ideológicas, estratégias discursivas de contra-argumentação e táticas de intervenção na esfera pública. A autora lem- 
bra que, para esse fim, essas organizações precisam contar em seus quadros, ou entre os seus colaboradores, com profissionais capacitados tanto na academia, quanto na aprendizagem coletiva das lutas sociais - das locais às globais.

O terceiro e último artigo da primeira seção, intitulado "Informação, rede e redes sociais - fundamentos e transversalidades", de Regina Marteleto, inicia situando histórica e epistemologicamente rede e informação enquanto conceitos transversais e interdisciplinares em relação à divisão e à fragmentação dos conhecimentos disciplinares modernos. Em seguida, ao relacionar o conceito de rede aos de informação-conhecimento-saber, procura abrir caminho para vislumbrar os lugares de seu emprego na ciência da informação, a partir da demarcação das instâncias de produção de conhecimentos como um campo social (P. Bourdieu) ou como enredamento de atores, veículos e instituições presentes nos processos de pesquisa (B. Latour). O conceito de redes sociais é discutido para explorar as possibilidades dos seu emprego para entender uma "terceridade" presente nos elos sociais e nos processos de produção de conhecimentos, acesso e uso de informações. A autora apresenta algumas conclusões e projeções para os estudos da informação no contexto das redes.
E para registrar o processo de expansão da temática das redes no campo da informação, apresentam-se, na segunda seção, artigos extraídos de pesquisas de doutorado e mestrado que empregaram o conceito e a metodologia de análise de redes sociais, seja para analisar os processos locais de inovação e gestão de conhecimentos e informações, ou para estudar redes de co-autoria na ciência da informação.

O artigo de Antonio Braz Silva e Marta Araújo, "Gestão do conhecimento e capital social: as redes e sua importância para as empresas", aborda o conceito de capital social, sua relação com as redes sociais e sua importância para a criação de conhecimento nas empresas. Para esse fim apresenta a análise de redes sociais (ARS) como método para o estudo das ligações relacionais entre atores sociais, que tanto podem ser pessoas, departamentos dentro de uma organização ou empresas de uma região, e os tipos de elos que se estabelecem entre eles. Os autores partem do pressuposto que, nas empresas, as ações dos indivíduos não são autônomas, mas dependem das relações sociais e das rotinas existentes. Por sua vez, a ação das próprias empresas depende de suas redes com outras empresas. Essas redes fazem parte do capital social empresarial, pois mesmo o capital social dos indiví- 
duos pode ser administrado em favor da organização. Os autores assinalam um incremento no uso da análise de redes sociais nos estudos de gestão do conhecimento nas empresas, que não é devidamente acompanhado da necessária compreensão do conceito de capital social.

O artigo seguinte, "Redes sociais, conhecimento e inovação localizada", de Maria Inês Tomaél, aborda o processo de inovação e a influência que recebe de seu meio, o que o torna dependente da interação social, que é preponderante para seu crescimento e solidificação. $O$ estudo teve como objetivo distinguir experiências de caráter localizado de inovação em um consórcio de exportação de móveis. Para tanto, empregou a metodologia de análise de redes sociais (ARS), que mapeia as interações entre atores, enfatizando medidas e fluxos de informação entre eles. Os resultados indicam que as redes sociais permeiam o compartilhamento da informação, a apropriação do conhecimento e sua adaptação para distintas realidades, processo que ocorre entre as empresas que participam do consórcio no âmbito da gestão de processos. Em virtude das empresas participantes do consórcio desenvolverem procedimentos similares para a inovação de gestão, a autora conclui que na rede social do consórcio a inovação de gestão é localizada.

Prosseguindo na temática das organizações e suas redes, o artigo de Wilson Costa e Marta Pinheiro "Redes sociais e compartilhamento de informação e conhecimento em aglomerações produtivas" apresenta um recorte da dissertação de mestrado onde se empregou a metodologia de análise de redes sociais para estudar uma aglomeração produtiva local (APL) na região de Ubá, em Minas Gerais. Os autores discutem se 0 arranjo produtivo local, enquanto rede social, é um espaço apropriado à inovação e se incrementa a competitividade, por meio da produção e compartilhamento de informações e conhecimentos entre empresas e dessas com seus aparatos institucionais de apoio.

O artigo "Redes em Ciência da Informação: evidências comportamentais dos pesquisadores e tendências evolutivas das redes de coautoria", de Wladmir Brandão, Fernando Parreiras e Antonio Braz Silva, discute as possibilidades e modos de emprego do conceito e método de análise de redes sociais no estudo das questões de informação, lembrando que na ciência da informação, técnicas de análise de redes sociais vêm sendo utilizadas para analisar o fluxo de informação em comunidades e a estrutura das redes de colaboração científica. No 
entanto, observam os autores, "aspectos evolutivos, que poderiam auxiliar na predição do comportamento dos atores e, conseqüentemente, da estrutura futura da rede, têm sido negligenciados". A partir dessas constatações, o artigo evidencia o comportamento dos pesquisadores do campo de ciência da informação no Brasil, recorrendo à análise da evolução de redes de coautoria na área, apresentando tendências que provocarão impactos na estrutura dessas redes nos próximos anos.

A terceira parte do fascículo é constituída de duas resenhas de livro e capítulo de livro que abordam a análise de redes sociais. Indicações bibliográficas que podem contribuir para a iniciação em redes sociais, no caso do capítulo, ou no aprimoramento dos conhecimentos sobre o tema, com a leitura do livro resenhado.

Por último, na quarta parte apresentam-se resumos de teses e dissertações que empregaram o conceito de redes e/ou redes sociais em questões de conhecimento e informação em diferentes contextos de aplicações nos anos recentes, obtidos por consulta aos Programas de Pós-Graduação em Ciência da Informação e de áreas afins.

O fascículo, como já se lembrou no início dessa apresentação, oferece uma amostra qualificada da discussão e do emprego do conceito e da metodologia de redes e redes sociais para o estudo do conhecimento, da informação, da comunicação e das diferentes configurações epistemológicas, sociais, culturais, econômicas e políticas que os sujeitos coletivos e as organizações do mundo globalizado desenham.

\section{REFERÊNCIAS}

PARROCHIA, D. Philosophie des réseaux. Paris: Presses Universitaires de France, 1993, p.31.

BOLTANSKI, L. ; CHIAPELLO, E. Le nouvel esprit du capitalisme. Paris: Gallimard, 1999. 